\title{
EMBRIOLOGIA DO SISTEMA NERVOSO CENTRAL: ASPECTOS CLÍNICOS
}

\author{
${ }^{1}$ Francis Moreira da Silveira \\ ${ }^{2}$ Prof Bensson Samuel, MD, PhD
}

\section{RESUMO}

A embriologia do sistema nervoso central (SNC) é um assunto amplo. A estrutura da embriologia, a embriogênese do cérebro e da medula espinhal, vários testes que podem ser realizados no útero para testar anomalias do SNC e problemas que podem ser encontrados durante a embriogênese, com particular atenção ao SNC. O objetivo deste estudo foi analisar estudos sobre embriologia do sistema nervoso central e os aspectos clínicos. Metodologia: Foi realizada uma pesquisa bibliográfica nas bases de dados PUBMED, SCIELO, GOOGLE ACADÊMICO, artigos publicados de 2012 a 2020, 15 artigos atenderam aos critérios de inclusão em estudos, relatos de casos e revisões sistemáticas, bem como de literaturas que foram desenvolvidas. Nessa pesquisa para coleta dos resultados foram utilizados os bancos de dados mais recentes existentes e estão descobrindo novas evidências para mudanças evolutivas no tamanho e no número de neurônios no sistema nervoso humano, bem como a reorganização celular e molecular de seus circuitos neurais. Salienta se os mecanismos de desenvolvimento do SNC, sua etiologia/fisiopatologia, as mudanças genéticas e moleculares subjacentes que geram essas diferenças estruturais e funcionais, revelaram também a descrição das doenças do SNC. Este estudo possibilitou identificar a importância do tratamento precoce e prevenção.

Palavras-chaves: Embriologia, Sistema nervoso central, Medula espinhal.

\section{INTRODUÇÃO}

O sistema nervoso central (SNC) é composto pelo cérebro e pela medula espinhal. Ambos se desenvolvem a partir do ectoderma embrionário ao lado de outras estruturas como a pele. Seu desenvolvimento começa já na $3^{\text {a }}$ e $4^{\underline{a}}$

\footnotetext{
1 *Médico Psiquiatra - Membro efetivo da associação Brasileira de Neuropsiquiatria E-mail: drfrancismsilveira@gmail.com

${ }^{2}$ Médico Norte Americano, Especialista, Mestre e Doutor - Membro da American Medical Association (Pennsylvania Medical License-US Medical License-MT 202650)
} 
semanas de vida embrionária, iniciando com o processo de neurulação, que é o desenvolvimento do tubo neural. O tubo neural fecha-se espontaneamente rostral e caudalmente. Da quinta à sexta semana, primeiro aparecimento do cérebro, segue-se o desenvolvimento prosencefálico. O cérebro primitivo é composto pelo prosencéfalo, mesencéfalo e rombencéfalo. O prosencéfalo se divide em telencéfalo e diencéfalo por meio de uma série de estágios de desenvolvimento, a saber: formação, clivagem e desenvolvimento da linha média. Qualquer forma de alteração do desenvolvimento nesses locais leva à malformação do cérebro em desenvolvimento (DIAS, PARTINGTON, 2015).

O artigo descreve a embriologia do sistema nervoso central, a malformação do desenvolvimento do córtex cerebral e da medula espinhal. A malformação do desenvolvimento do cérebro e da medula espinhal leva a uma variedade de doenças da microcefalia à espinha bífida. Os estágios de desenvolvimento do córtex cerebral abrangem três etapas principais (DIAS, PARTINGTON, 2015). Defeitos em uma ou em uma combinação dessas etapas formam a base da classificação da anormalidade do desenvolvimento cortical como:

A proliferação de células neurais: uma proliferação anormalmente alta de células neurais pode levar à megalencefalia, e a proliferação diminuída leva à microcefalia. Migração neuronal: o resultado da migração neuronal parcial é a heterotopia e a lissencefalia, a migração neuronal excessiva causa a malformação do paralelepípedo (DIAS, PARTINGTON, 2015).

De acordo com Gaitanis, Tarui (2018) a organização cortical pósmigracional e conectividade: eventos irregulares na organização cortical pósmigracional causam displasias corticais focais e polimicrogiria. Os defeitos da fusão do tubo neural consistem em encefalocele, meningocele, mielomeningocele e espinha bífida oculta. Especificamente, as alterações no fechamento do tubo neural rostral resultam em condições como anencefalia ou encefalocele. A mielomeningocele ocorre a partir da fusão causal incompleta do tubo neural. A anencefalia geralmente ocorre antes do $24^{\circ}$ dia de vida, enquanto a encefalocele e a mielomeningocele ocorrem por volta do $26^{\circ}$ dia de vida (GAITANIS, TARUI, 2018). 
Uma pesquisa qualitativa e descritivo é o método de pesquisa, dados científicos publicados nos últimos anos que avalia informações sobre opiniões e valores, ao contrário dos dados estatísticos. Segundo GIL (2007) a análise descritiva contribui ao pesquisador verificar, examinar, registrar e explicar as situações sem intervir diretamente neles, detalhando características de um acontecimento no qual o pesquisador deve dispor um domínio e conhecimento sobre os assuntos e as dúvidas a serem investigadas.

Para isto, na pesquisa dos dados, foi criado um arcabouço analítico para reunir e sintetizar as principais informações dos estudos, seguido pela interpretação e comparação entre produções e elementos que compõem cada um, encontrando informações e evidências significativas sobre a embriologia do sistema nervoso central e os aspectos clínicos, bancos de dados GOOGLE ACADÊMICO, SCIELO e PUB, publicados nos últimos anos com os seguintes temas: Embriologia, Sistema nervoso central, Medula espinhal.

\section{DESENVOLVIMENTO}

\subsection{Desenvolvimento do sistema nervoso central}

O desenvolvimento embriológico é um processo intrincado, sendo a formação do sistema nervoso humano apenas um componente, embora vital. $O$ desenvolvimento de nossos corpos nos torna o que somos; mas o desenvolvimento de nossos cérebros nos torna quem somos, dando-nos a capacidade de pensar, ver, sentir (tanto física quanto emocionalmente), etc (GAITANIS, TARUI, 2018).

O sistema nervoso possui vários elementos, cada um dos quais, quando totalmente formado e ativo, terá responsabilidades diferentes. O sistema nervoso central (SNC) é composto pelo cérebro e pela medula espinhal. O cérebro interpreta as informações recebidas pela medula espinhal e gera seus próprios sinais e instruções para que o corpo as execute. A medula espinhal transmite informações do cérebro para o corpo e vice-versa (GUERRINI, DOBYNS, 2014).

O sistema nervoso periférico (SNP) consiste em todos os neurônios fora do cérebro e da medula espinhal, incluindo os nervos cranianos e os nervos 
espinhais. Esses nervos são aferentes (ou seja, sinais de recepção sensorial no corpo a serem transmitidos para processamento no cérebro) ou eferentes (motor, fornecendo sinais do cérebro para o corpo) (GUERRINI, DOBYNS, 2014).

Segundo Marin-Valencia, Guerrini, Gleeson (2014) finalmente, o sistema nervoso autônomo (SNA), que é composto em parte pelo SNC e em parte pelo SNP, contém neurônios que suprem o músculo cardíaco, o músculo liso e as glândulas. O SNP tem dois componentes: o sistema nervoso simpático fornece sinais para o corpo se preparar para "lutar ou fugir"; e o sistema nervoso parassimpático sinaliza ao corpo que ele pode "descansar e digerir".

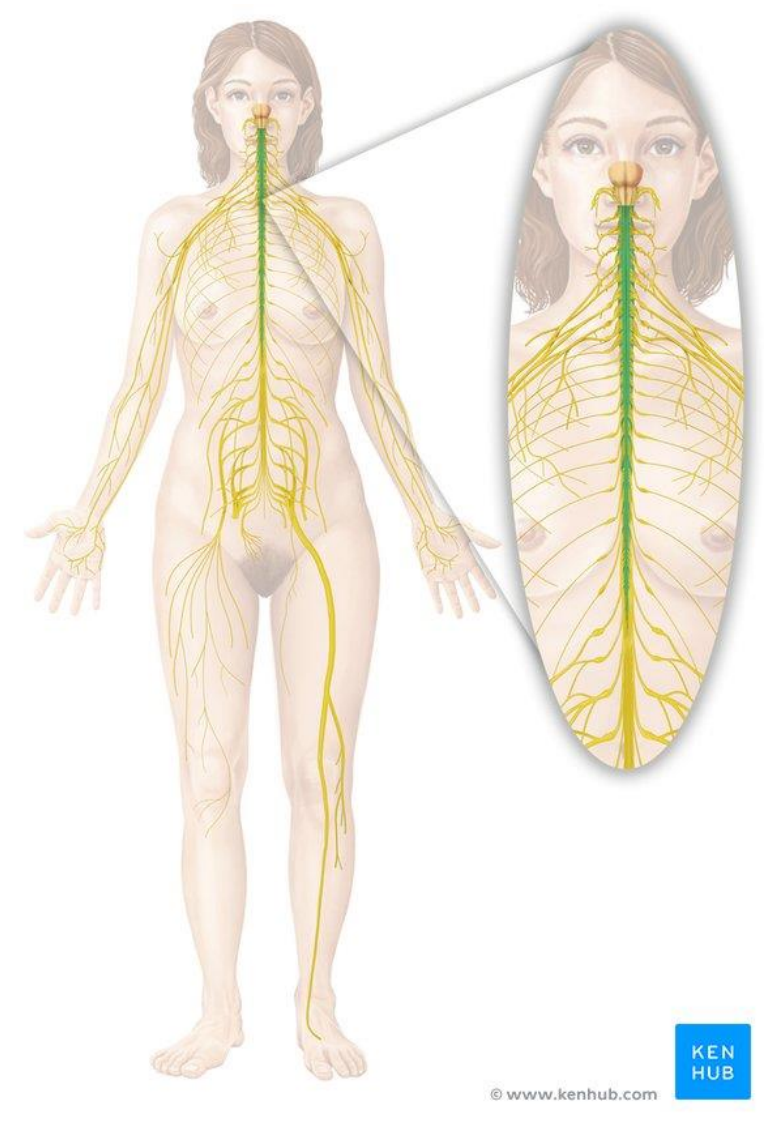

Imagem 1: Medula espinhal (vista ventral) Fonte: (MARIN-VALENCIA, GUERRINI, GLEESON, 2014).

\subsubsection{Desenvolvimento precoce}

Nos primeiros estágios de desenvolvimento, três camadas icônicas de tecido se desenvolvem dentro do embrião: o endoderma, o mesoderma e o ectoderma (MARIN-VALENCIA, GUERRINI, GLEESON, 2014). 
O sistema nervoso se desenvolve a partir de uma seção da ectoderme chamada placa neural, que começa a se diferenciar sob a influência do notocórdio próximo e do mesoderma paraxial por volta da terceira semana. As bordas da placa neural então se elevam para formar as dobras neurais. Em um processo chamado neurulação, as dobras neurais se curvam para cima e se fundem para formar o tubo neural, que eventualmente se tornará o SNC. A placa neural também forma a crista neural, cujas células mais tarde migrarão para diferentes partes do corpo e se tornarão a maioria das células do SNP e do SNA (MARIN-VALENCIA, GUERRINI, GLEESON, 2014).

A neurulação começa na quarta semana de desenvolvimento (em torno do dia 22-23). As dobras neurais se fundem primeiro na região cervical e continuam a se fundir nas direções cranial (cabeça) e caudal (cauda) até que apenas as extremidades do tubo permaneçam abertas e conectadas com a cavidade amniótica (GUTIERREZ-CASTILLO et al., 2018).

Essas aberturas são chamadas de neuroporos, sendo a abertura na extremidade cranial do embrião o neuroporo rostral e a abertura na extremidade caudal sendo o neuroporo caudal. O neuroporo rostral fecha por volta do $25^{\circ}$ dia, e o neuroporo caudal fecha aproximadamente dois dias depois (GUTIERREZCASTILLO et al., 2018).

O tubo neural se torna vascularizado no momento em que os neuroporos fecham. As regiões do tubo neural começam a engrossar, formando o cérebro e a medula espinhal, e a abertura dentro do tubo começa a formar os ventrículos e o canal medular central (PETRYK, GRAF, MARCUCIO, 2015).

Durante esse período de desenvolvimento, certos genes se tornam vitais para garantir o layout estrutural preciso do SNC: hedgehog sônico (Shh), os genes Pax, proteínas morfogênicas ósseas e um fator de crescimento transformador (TGF-B) chamado dorsalina. Esses componentes são todos influentes na padronização dorsoventral adequada do tubo neural em desenvolvimento (PETRYK, GRAF, MARCUCIO, 2015). 


\subsection{Etiologia/fisiopatologia}

Vários estudos implicaram fatores ambientais na malformação do sistema nervoso central de um embrião. Isso inclui deficiência de folato, uso de drogas ilícitas e prescrição de medicamentos que afetam o metabolismo do folato no corpo (DESIKAN, BARKOVICH, 2016).

\subsection{Mecanismo Celular/Bioquímico/Molecular (A via PI3K-AKT3-TSC2-mTOR)}

Fatores genéticos e moleculares podem interromper o desenvolvimento normal do córtex cerebral. Qualquer forma de alteração nos genes que controlam o crescimento e as vias metabólicas leva à malformação do desenvolvimento cortical. Geralmente, a via do alvo da rapamicina em mamíferos (mTOR) foi fortemente reconhecida nessas malformações. A inibição de TSC ou ativação de PIK3CA ou AKT3 hiperativa a via mTOR está levando ao crescimento celular desregulado (DESIKAN, BARKOVICH, 2016; ETHEREDGE et al., 2012).

A maioria dos defeitos do tubo neural são esporádicos. Fatores genéticos permanecem fortemente implicados na patogênese dos Defeitos do tubo neural (DTNs), e a forma usual de herança é multifatorial ou poligênica. A deficiência materna de folato pode contribuir para o desenvolvimento de DTN em indivíduos geneticamente suscetíveis. Estudos têm mostrado que mutações nos genes envolvidos no metabolismo mitocondrial do folato aumentam o risco. O gene 5,10-metilenotetra-hidrofolato redutase (MTHFR) e sua forma variante (genótipo C677T) (MTHFR C677T) estão associados ao risco de DTNs. O nível de folato materno é um fator de risco; no entanto, apenas um número inconsequente de casos. Em muitos casos, os níveis maternos de folato estão dentro da faixa normal ou dificilmente são clinicamente deficientes. $O$ folato facilita o transporte de unidades de um carbono da mitocôndria para o citoplasma e desempenha um papel vital na biossíntese e metilação do nucleotídeo (DESIKAN, BARKOVICH, 2016).

\subsection{Malformação de desenvolvimento do córtex cerebral}

\subsubsection{Holoprosencefalia}


Holoprosencefalia é uma malformação do prosencéfalo caracterizada pela separação incompleta de ambos os hemisférios cerebrais. Anormalidades cromossômicas, como as síndromes de Patau e Edward, apresentam um risco maior de holoprosencefalia, bem como de gestação complicada com diabetes. A síndrome de Patau (trissomia do cromossomo 13) é a síndrome mais comumente associada (ETHEREDGE et al., 2012).

A holoprosencefalia geralmente é incompatível com a vida, e a maioria das crianças nascidas com essa malformação apresenta mortalidade muito alta no início da vida pós-natal. Os subtipos de holoprosencefalia em ordem crescente de gravidade são as variantes inter-hemisférica média, lobar, semilobar e alobar. Uma tomografia computadorizada de cérebro ou ressonância magnética pode ser usada para confirmar o diagnóstico e diferenciar os subtipos de holoprosencefalia. [13] Suspeita-se que genes como a Proteína Morfogenética Óssea (BMP), Sonic hedgehog (Shh), Fator de Crescimento de Fibroblastos (FGF) estejam associados à holoprosencefalia (ETHEREDGE et al., 2012).

\subsubsection{Agenesia do corpo caloso (ACC)}

Segundo Lerman-Sagie, Leibovitz (2016) ACC é um desenvolvimento parcial ou ausência completa do corpo caloso, que é a estrutura de conexão entre os dois hemisférios cerebrais. Uma mutação frameshift (perda de função) do gene do receptor DCC Netrin 1 se correlaciona com a agenesia do corpo caloso, e a maioria dos casos não apresentava sintomas neurológicos. As manifestações clínicas e radiológicas desta doença variam; A ressonância magnética é uma boa modalidade de imagem para o diagnóstico. Estudos têm mostrado que uma forte conexão entre indivíduos com ACC tem muitas características comuns ao autismo, como a estereotipia. O comportamento antisocial e a mentira também são uma característica comumente relatada na disgenesia calosa.

\subsubsection{Displasia séptica}

Esta condição é uma anormalidade do prosencéfalo que é composta pela tríade de um defeito nas estruturas da linha média do prosencéfalo - septo 
pelúcido n (com ou sem agenesia do corpo caloso), hipoplasia do nervo óptico (nervo craniano II) e insuficiência pituitária. É mais provável que ocorra entre a $4^{\text {a }}$ e $6^{\underline{a}}$ semanas de vida. É uma condição incomum, com incidência de 1 em 10.000 nascidos vivos. Ele tem links com uma mutação no HESX1, SOX2 e SOX3 ou OXT2. Estes produzem uma constelação de sintomas neurológicos, como anormalidades do nervo óptico, como nistagmo e características de produção de sintomas clínicos, insuficiências hipofisárias (LERMAN-SAGIE, LEIBOTITZ, 2016; KRUSZKA, MUENKE, 2018).

\subsubsection{Megalencefalia}

Megalencefalia é um tamanho de cabeça aumentado acima de dois desvios-padrão. Clinicamente, é mais aplicável defini-lo como o tamanho do cérebro maior do que três desvios-padrão acima da média para excluir a megalencefalia familiar. Ocorre devido a defeitos congênitos na migração neuronal ou proliferação celular anormal ou uma combinação de ambos. A megalencefalia é classificada com base na etiologia, anomalias genéticas no metabolismo e desenvolvimento. Mutações em genes que controlam as principais vias moleculares, como a fosfatidilinositol 3-quinase (PI3K/AKT), foram implicadas. Por outro lado, a megalencefalia requer diferenciação da macrocefalia, que é um aumento incomum na circunferência occipitofrontal (COF), pelo menos, dois desvios padrão causados por anormalidades estruturais do crânio, cérebro ou líquido cefalorraquidiano (LCR) e estruturas relacionadas (LERMAN-SAGIE, LEIBOTITZ, 2016; KRUSZKA, MUENKE, 2018).

\subsubsection{Hemimegalencefalia}

Este é um aumento unilateral do hemisfério cerebral envolvendo parte ou todo o hemisfério cerebral. Comumente observada em associação com síndromes neurocutâneas hemimegaloencefalia, como síndrome sebácea linear, esclerose tuberosa e neurofibromatose. A apresentação comum dessa doença inclui retardo psicomotor, convulsões intratáveis, paralisia dos nervos cranianos e hemiparesia. A presença de convulsões no primeiro ano de vida é indicativa de mau prognóstico. Vários estudos identificaram mutações em genes que 
controlam as principais vias moleculares, como a fosfatidilinositol 3-quinase (PI3K/AKT) -mTOR (SHE et al., 2019).

\subsubsection{Heterotopia Periventricular}

Esta patologia é uma doença genética devido a uma falha de migração dos neurônios, levando a nódulos localizados de forma anormal ao redor dos ventrículos. A manifestação clínica mais comum é uma convulsão afebril. A pesquisa mostrou que ocorre ao lado de outras condições como EDS, síndrome de Williams e Ci du Chat. No entanto, mutações na filamina A (FLNA (Xq28) e no fator de ribosilação do ADP, fator de troca de nucleotídeo guanina 2 (ARFGEF2 (20q13). FLNA ligado ao X enquanto o ARFGEF2 autossômico recessivo (SHE et al., 2019).

\subsubsection{Lissencefalia-paquigiria}

A lissencefalia-paquigiria é um espectro de desenvolvimento anormal dos giros e sulcos cerebrais resultante da migração anormal de neurônios. O termo para desenvolvimento parcial é paquigiria e ausência total é agiria. A paquigiria geralmente apresenta sintomas mais brandos em comparação com a lisencefalia. O tipo um é conhecido como lisencefalia clássica e o tipo dois é o complexo de paralelepípedos. A malformação lisencefalia do paralelepípedo está associada às mutações dos genes TUBA1A e GPR56. O defeito do paralelepípedo é resultado da combinação da migração excessiva de células da crista neural para as leptomeninges e anormalidades na superfície da camada de pia cerebral. As mutações genéticas mais comuns implicadas na lissencefalia são LIS1 e DCX. Outros incluem proteínas de estrutura celular, como genes de actina, dineína, cinesina, tubulina, CASP2 e adaptador contendo domínio RIPK1 com domínio de morte (CRADD) (SIFFREDI et al., 2019; SAGI et al., 2020).

\subsubsection{Polimicrogiria}

Como o nome indica, é simplesmente um córtex cerebral anormalmente formado que possui vários pequenos giros. A gravidade dos sintomas está fortemente relacionada à extensão do envolvimento do cérebro com a variante focal unilateral como a forma mais branda da doença. Tem poucos ou nenhum 
sintoma e é controlado principalmente com medicamentos antiepilépticos. A mais grave é a polimicrogiria frontoparietal bilateral com manifestações neurológicas significativas. Essa forma grave é herdada em um padrão autossômico recessivo e o defeito está no cromossomo 16q12-21 (SIFFREDI et al., 2019).

A polimicrogiria é comumente associada às síndromes de Aicardi, Delleman, DiGeorge 22q11.2 (deleção), Sturge-Weber e Warburg Micro. Mutações em genes que controlam as principais vias moleculares, como a fosfatidilinositol 3-quinase (PI3K/AKT), foram implicadas. Os pesquisadores também notaram que a lissencefalia do paralelepípedo é comumente associada à polimicrogiria. (25047116). A esquizencefalia geralmente é classificada como um subtipo de polimicrogiria e é uma malformação cerebral rara, descrita como cérebro dividido ou fenda que atravessa a pia-máter cerebral até os ventrículos (SAGl et al., 2020).

\subsubsection{Displasia Cortical Focal}

Displasias corticais focais (DCFs) é um nome abrangente que consiste em vários subgrupos de laminação anormal do córtex cerebral. Demonstrou ser a causa mais frequente de convulsões, não passível de medicamentos. A DCF geralmente é mais prevalente em homens do que em mulheres. O DCF tipo I é uma ausência anormal de laminação cortical. Se ocorrer em padrões radiais, é subclassificado como la e lb se tangencial, lc, por outro lado, é uma combinação de ambos os padrões. Em contraste, para o tipo I, que é leve e mais provável em adultos, o DCF tipo II é mais clinicamente grave e observado mais em crianças (PATRA, NAIK, JHA, 2019).

Fortes ideias foram avançadas para demonstrar que esclerose tuberosa 1 e 2 (TSC1 e TSC2), bem como genes homólogos de fosfatase e tensina (PTEN) que regulam mTOR, também são as causas de FCD tipo $2 b$ porque compartilha características comuns com esclerose tuberosa (PATRA, NAIK, JHA, 2019).

O FCD tipo III é do tipo I ou II que ocorre simultaneamente com outras lesões cerebrais. Se a esclerose do hipocampo estiver presente, ela será ainda 
classificada como IIla, com tumores como IIlb, malformações vasculares como Illc e insultos patológicos extrínsecos, como hipóxia, trauma e encefalite como IIId (PATRA, NAIK, JHA, 2019).

\subsection{Malformação de desenvolvimento da medula espinhal}

Os defeitos do tubo neural (DTNs) são malformações do cérebro e da medula espinhal como resultado da falha do fechamento do tubo neural na terceira e quarta semanas de desenvolvimento intrauterino. Eles são a malformação congênita mais prevalente do SNC. Embora a suplementação de ácido fólico pré-natal de rotina tenha sido eficaz na redução da prevalência da doença, ela continua sendo uma das anormalidades mais comuns do recémnascido. Existem duas formas principais de DTNs, que são a anencefalia e a espinha bífida (ROXANAS, MASSEY, CHAGANTI, 2014).

A espinha bífida é um DTN comum em que a medula espinhal é exposta ou se projeta para a superfície com as meninges em forma de saco por meio de um defeito na parede vertebral. Inclui mielomeningocele, meningocele e mielocele. Quando esse defeito de fechamento envolve a herniação apenas do líquido cefalorraquidiano, é denominado mielocele, a mielocele contendo meninges é a meningomielocele e, com as meninges e a medula espinhal, é denominada mielomeningocele. Comumente associados à espinha bífida estão a hidrocefalia e a malformação de Arnold-Chiari tipo II (uma combinação de mielomeningocele e hérnia de tonsila cerebelar) (ROXANAS, MASSEY, CHAGANTI, 2014).

A anencefalia é um dos tipos comuns de DTNs com ausência congênita do cérebro ou de partes do cérebro e do crânio. Ocorre como resultado da falha da porção craniana do fechamento do tubo neural (TAN et al., 2018).

Encefalocele é um DTN raro no qual o cérebro se projeta através de uma abertura anormal do crânio com ou sem as meninges, deixando uma projeção de uma estrutura semelhante a uma bolsa na cabeça. Também é frequentemente associada a outras anormalidades do SNC, como hidrocefalia, especialmente com as encefaloceles posteriores. Essa condição pode ser o 
resultado de estenose aquedutal ou torção e também pode ser uma complicação pós-cirúrgica do reparo de encefalocele (TAN et al., 2018).

\subsection{Investigação/tratamento}

A maioria das malformações do sistema nervoso central (SNC) são reconhecíveis durante a triagem laboratorial de rotina e exames de ultrassom. Uma elevação de alfa-fetoproteína (AFP) no segundo trimestre na triagem tripla levanta uma suspeita muito alta de defeitos do tubo neural. Uma investigação diagnóstica adicional será necessária se alguma anormalidade for detectada. $\mathrm{O}$ tratamento requer de malformação congênita do SNC requer uma abordagem multidisciplinar e manejo de suporte, como antiepilépticos, tubos de gastrostomia e outras modalidades cirúrgicas. A prevenção mais amplamente praticada para bífida espinhal é a suplementação de ácido fólico com o uso pré-concepção mais benéfico do que o uso na gravidez. Na espinha bífida, a medula espinhal fica exposta ao líquido amniótico que contribui para o dano adicional dos tecidos nervosos. Procedimentos cirúrgicos intrauterinos recentemente praticados para prevenir a neurodegeneração da medula espinhal exposta têm sido muito úteis na preservação das estruturas e na melhoria dos resultados (TAN et al., 2018).

\section{CONCLUSÃO}

O estudo foi de extrema importância, possibilitou uma investigação mais contemplativa sobre a embriologia do sistema nervoso central, demonstrou-se que o sistema nervoso, em particular o cérebro e suas habilidades cognitivas, está entre os atributos mais distintos e impressionantes dos humanos. Não é bem compreendido como o sistema nervoso mudou na linhagem humana e como ele difere daquele de primatas intimamente relacionados.

Considerando os bancos de dados mais recentes de espécies existentes estão descobrindo novas evidências para mudanças evolutivas no tamanho e no número de neurônios no sistema nervoso humano, bem como a reorganização celular e molecular de seus circuitos neurais. O estudo traz a relevância dos mecanismos de desenvolvimento do SNC, sua etiologia/fisiopatologia, as mudanças genéticas e moleculares subjacentes que geram essas diferenças 
estruturais e funcionais, revelaram também a descrição das doenças do SNC bem como a importância do tratamento precoce e prevenção.

À medida que novas informações e ferramentas relevantes se materializam em um ritmo sem precedentes, o campo está maduro para estudos sistemáticos e funcionalmente relevantes do desenvolvimento e evolução das especializações do sistema nervoso humano. Diante de tudo o que foi exposto neste trabalho, faz-se necessário a realização de novos estudos a fim de compreender.

\section{Embryology of the central nervous system: clinical aspects}

\section{Abstract}

The embryology of the central nervous system (CNS) is a broad subject. The structure of embryology, embryogenesis of the brain and spinal cord, various tests that can be performed in the uterus to test for CNS abnormalities and problems that can be encountered during embryogenesis, with particular attention to the CNS. The aim of this study was to analyze studies on central nervous system embryology and clinical aspects. Methodology: A bibliographic search was carried out in the PUBMED, SCIELO, GOOGLE ACADÊMICO, articles published from 2012 to 2020, 15 articles met the inclusion criteria in studies, case reports and systematic reviews, as well as literature that were developed. In this research to collect the results, the most recent existing databases were used and are discovering new evidence for evolutionary changes in the size and and molecular reorganization of their neural circuits. We also discussed the mechanisms of CNS development, its etiology/pathophysiology, the underlying genetic and molecular changes that generate these structural and functional differences, also revealed the description of CNS diseases. This study made it possible to identify the importance of early treatment and prevention.

Keywords: Embryology, Central nervous system, Spinal cord. 


\section{REFERÊNCIAS BIBLIOGRÁFICAS}

Desikan RS, Barkovich AJ. Malformações do desenvolvimento cortical. Ann Neurol. Dezembro de 2016.

Dias $M$, Partington $M$., SEÇÃO SOBRE CIRURGIA NEUROLÓGICA. Malformações congênitas do cérebro e da medula espinhal e seus marcadores cutâneos associados. Pediatria. 2015

Etheredge AJ, Finnell RH, Carmichael SL, Lammer EJ, Zhu H, Mitchell LE, Shaw GM. Interações gene-folato materno e infantil e o risco de defeitos do tubo neural. Am J Med Genet A. Out. 2012.

Gaitanis J, Tarui T. Nervous System Malformations. Continuum (Minneap Minn). 2018.

Guerrini R, Dobyns WB. Malformações do desenvolvimento cortical: características clínicas e causas genéticas. Lancet Neurol. 2014.

Gutierrez-Castillo A, Jimenez-Ruiz A, Chávez-Castillo M, Ruiz-Sandoval JL. Síndrome da Displasia Septo-óptica Plus. Cureus. 2018.

Kruszka P, Muenke M. Syndromes associated with holoprosencephaly. Am J Med Genet C Semin Med Genet. Junho de 2018.

Lerman-Sagie T, Leibovitz Z. Malformations of Cortical Development: From Postnatal to Fetal Imaging. Can J Neurol Sci. Setembro de 2016.

Marin-Valencia I, Guerrini R, Gleeson JG. Mecanismos patogenéticos da displasia cortical focal. Epilepsia. 2014.

She Q, Fu F, Guo X, Tan W, Liao C. Teste genético em fetos com agenesia isolada do corpo caloso. J Matern Fetal Neonatal Med. 27 de agosto de 2019.

Siffredi V, Wood AG, Leventer RJ, Vaessen M, Mcllroy A, Anderson V, Vuilleumier $P$, Spencer-Smith MM. Anterior and posterior commissures in 
agenesis of the corpus callosum: Alternative pathways for attention processes? Cortex. 2019 Dec.

Represa A. Por que as malformações do desenvolvimento cortical causam epilepsia. Front Neurosci. 2019.

Roxanas MG, Massey JS, Chaganti J. Comportamento anti-social e mentira: uma apresentação neuropsiquiátrica da agenesia do corpo caloso. Australas Psychiatry. Outubro de 2014.

Sagi-Dain L, Kurolap A, Ilivitzki A, Mory A, Paperna T, Regeneron Genetics Center. Kedar R, Gonzaga-Jauregui C, Peleg A, Baris Feldman H. A novel heterozygous loss-of-function DCC Netrin 1 receptor variant in prenatal agenesis of corpus callosum and review of the literature. Am J Med Genet A. 2020 Jan.

Patra S, Naik S, Jha M. Corpus Callosum Agenesis: Neuroanatomical Model of Autism Spectrum Disorder? Indian J Psychol Med. 2019.

Petryk A, Graf D, Marcucio R. Holoprosencefalia: sinalizando as interações entre o cérebro e a face, o meio ambiente e os genes, e a variabilidade fenotípica em modelos animais e humanos. Wiley Interdiscip Rev Dev Biol. 2015.

Tan AP, Mankad K, Gonçalves FG, Talenti G, Alexia E. Macrocefalia: Resolvendo o Dilema Diagnóstico. Imagens de ressonância magnética superiores. 2018. 